\section{EMBRYRIDDLE \\ Aeronautical University}

SCHOLARLY COMMONS

\section{International Journal of Aviation,} Aeronautics, and Aerospace

\title{
A Comparative Aerodynamic study of Nonplanar Wings
}

Mondher Yahyaoui

LASMAP Laboratory at Tunisia Polytechnic School \& Ecole d'aviation de Borj El Amri, Tunisia., mondher_yahia@yahoo.fr

Follow this and additional works at: https://commons.erau.edu/ijaaa

Part of the Aerodynamics and Fluid Mechanics Commons

\section{Scholarly Commons Citation}

Yahyaoui, M. (2019). A Comparative Aerodynamic study of Nonplanar Wings. International Journal of Aviation, Aeronautics, and Aerospace, 6(4). https://doi.org/10.15394/ijaaa.2019.1383

This Article is brought to you for free and open access by the Journals at Scholarly Commons. It has been accepted for inclusion in International Journal of Aviation, Aeronautics, and Aerospace by an authorized administrator of Scholarly Commons. For more information, please contact commons@erau.edu. 


\section{Introduction}

Vortex drag accounts for about $40 \%$ of commercial jet transport at cruise conditions and for 80-90\% at low speed (Kroo, 2005). The induced drag of plain monoplanes can only be optimized to the extent of having a unit span efficiency factor by achieving an elliptic lift distribution in the spanwise direction. Therefore, in recent years, nonplanar wing configurations have received renewed research interest in view of their potential for attaining much higher values of span efficiency factor and providing major reduction in induced drag.

The idea of nonplanar wings goes back to almost a century ago (Prandtl, 1924) when it was shown that a box wing, which is basically a biplane connected by end plates, generates less induced drag than other configurations at given lift and span. This configuration was referred to as the best wing system (BWS). According to Prandtl's study, for a height-to-span ratio of 0.2 , box wings generate only $68 \%$ of the induced drag of a monoplane of equal lift and span. This is equivalent to an overall $12.8 \%$ drag reduction in cruise flight (32\% of $40 \%)$ of a typical jet transport aircraft, and a reduction of $25.6-28.8 \%$ at low speeds. These reductions will increase to $16 \%$ at cruise speed and $32-36 \%$ at low speeds if the fence height-to-span ration in increased to 0.3. Adding surface extensions to basic wings to obtain nonplanar wing configurations such as box wings, $\mathrm{C}$-wings or wing-winglets adds profile drag by increasing wetted area. In addition, for the case of box wings, maintaining equal span and planform area reduces the average chord by half and lowers the wings' Reynolds number, which in turn increases local skin friction. But this is by no means the only drawback associated with box wings.

An early investigation into the possibility of integrating box wings into transonic transport (Lange et al., 1974) revealed a number of issues that needed to be resolved, in particular the problem of aeroelastic instabilities at a relatively low flutter speed known to be associated with forward swept wings. Kroo (2005) presented an interesting discussion of the potential for overall aircraft performance improvement associated with nonplanar wing configurations. The main point made was that nonplanar concepts should not be evaluated from an induced drag reduction perspective alone. Other aspects such as the wings structural features may improve overall performance by reducing structural weight.

In spite of the many unsolved issues relating to stability, aeroelastic behavior, and structural efficiency, nonplanar wing configurations have been the subject of numerous aerodynamic studies. Most of these studies are based in the Treftz plane and use a discrete vortex lattice method to determine the optimal spanwise lift distribution which yields minimum induced drag (Blackwell, 1976; Lamar, 1976; Kroo, 2004; Kuhlman \& Ku, 1982). As shown in Figure 1, the 
spanwise distribution of wing and fin twist for minimum induced drag is in general highly varying which makes it of limited practical interest in aircraft construction.

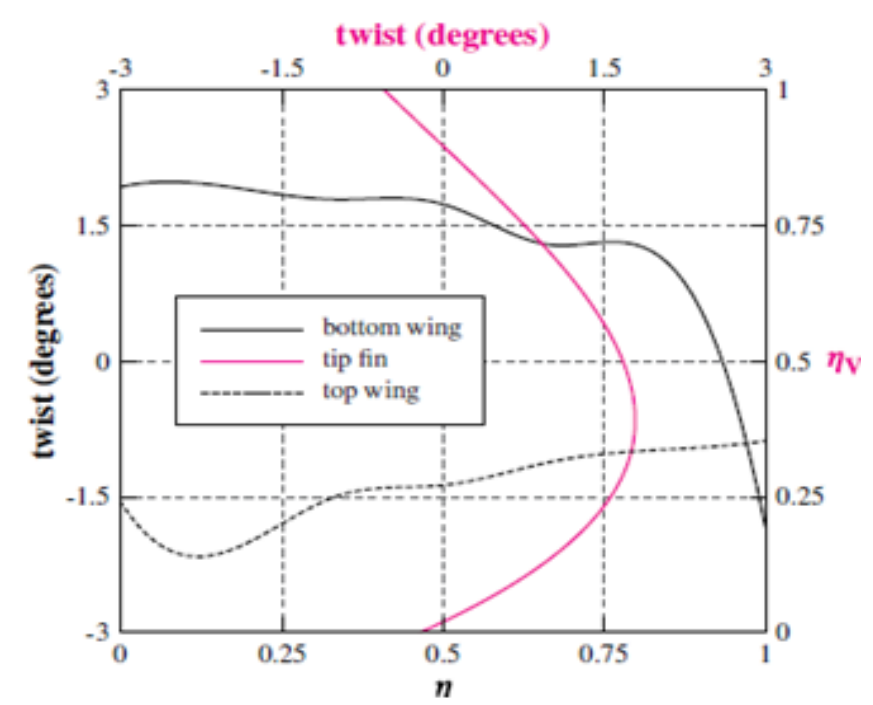

Figure 1. Example of optimal twist distribution for a box wing. Adapted from "Aerodynamic Optimization Trade Study of a Box-Wing Aircraft Configuration," by H. Gagnon and D. W. Zingg, 2016, AIAA.

The objective of the present work is to show that it is possible to achieve the same higher values of span efficiency published in various research papers using only the more practical linear twist for the upper and lower wings and the tip fin. Four nonplanar wing configurations were considered (Figure 2) and the effect of other geometric parameters such as angle of attack, fin height-to-span ratio, sweep, aspect ratio, stagger, and the ratio of the winglet/fin bottom chord to wing tip chord were also studied.

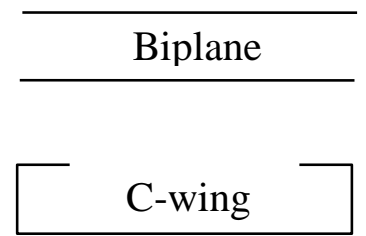

\section{Wing-winglet}

Box wings

Figure 2. The four nonplanar wings considered.

It is also the purpose of this study to make a comparison between the different configurations based on the lowest induced drag criteria. Establishing empirical equations for the induced drag ratio as a function of fin height-to-span 
ratio is another objective. The investigation is conducted using a cambered VLM program developed by the author (Yahyaoui, 2014/2019). The main results are given in the form of graphical representation of the span efficiency factor of the different configurations as functions of the various geometric parameters considered.

\section{Numerical Method and Validation}

The vortex-lattice method used in this investigation is a singularity method which has been around for many decades and is well documented in the literature (Bertin \& Smith, 2009). Our VLM MATLAB code accommodates the four configurations subject of this investigation but can also be easily adjusted to include other non planer configurations. While the induced drag coefficient is directly provided by the VLM code, the profile drag coefficient is computed using the equation (Figure 3):

$$
\begin{aligned}
& C_{D_{p}} \\
& =\frac{2}{S} \int_{0}^{s_{B}} C_{d}(s) c(s) d s
\end{aligned}
$$

where $S$ is the wing reference area, $s$ is the curvilinear coordinate following the wing span, and $C_{d}$ is the section profile drag coefficient which depends on the local angle of attack $\alpha(s)$ and the Reynolds number based on the local chord $c(s)$. Numerical values for the local profile drag coefficient are estimated through interpolation using experimental data curves (Abbott \& Von Doenhoff, 1959).

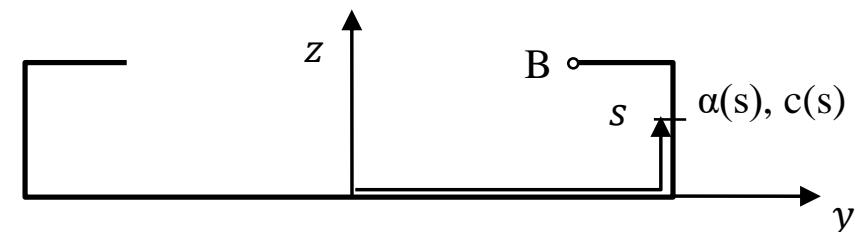

Figure 3. The setup for computing the profile drag of a typical nonplanar wing.

The key geometric parameters that can be specified for a non planar wing configuration are given in Figure 4. These are:

- The angle of attack at the root of the lower wing $\left(\alpha_{r_{l}}\right)$.

- The angle of attack at the inner end of the upper wing $\left(\alpha_{r_{u}}\right)$. When a box wing is considered, this angle is the angle at the root of the upper wing.

- The twist angle for lower and upper wings $\left(\theta_{l}, \theta_{u}\right)$.

- The twist angle for the winglet/fin $\left(\theta_{w}, \theta_{f}\right)$.

- The winglet/fin cant angle $\left(\delta_{c}\right)$.

- The height-to-span ratio $\left(h_{b}\right)$. 
- The ratio of the upper-wing span to lower wing span $\left(K_{b}=b_{u} / b_{l}\right)$.

- The ratio of the winglet/fin bottom chord to the lower-wing tip chord $\left(K_{c}=\right.$ $\left.c_{b_{w}} / c_{t_{l}}\right)$.

- Other classical parameters such as aspect ratio (A), sweep $(\Lambda)$, and taper ratio $(\lambda)$.

An example of wing configuration treated by our code is shown in Figure 5.

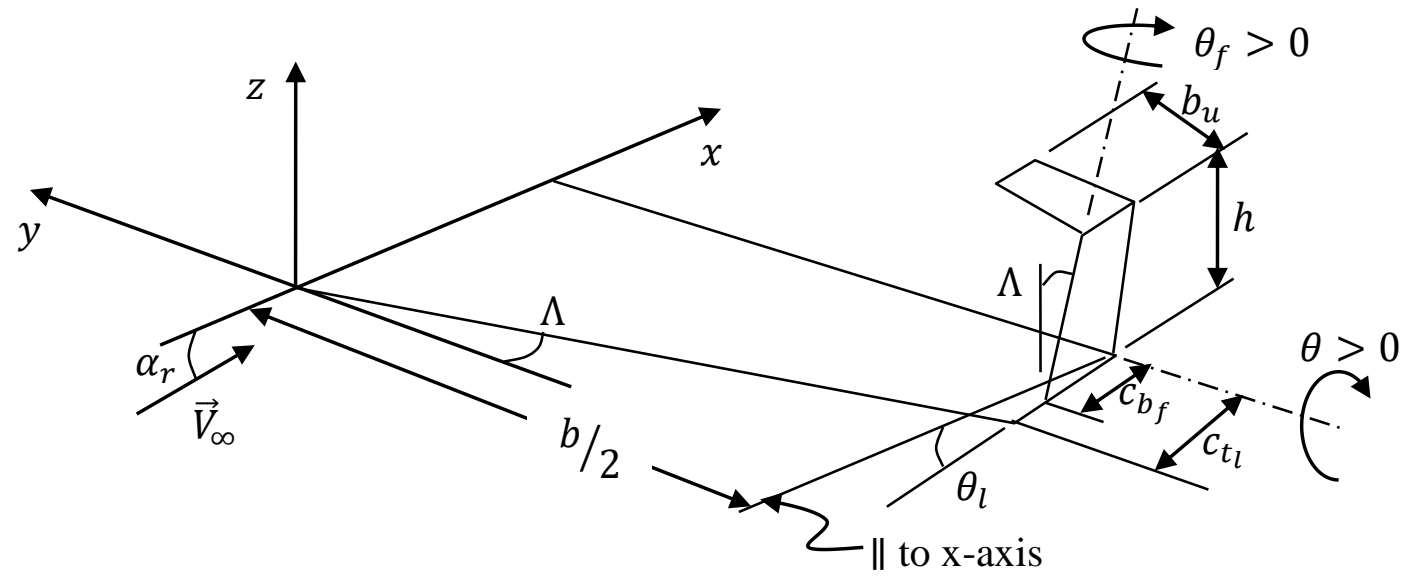

Figure 4. Key geometric parameters defining nonplanar wings.

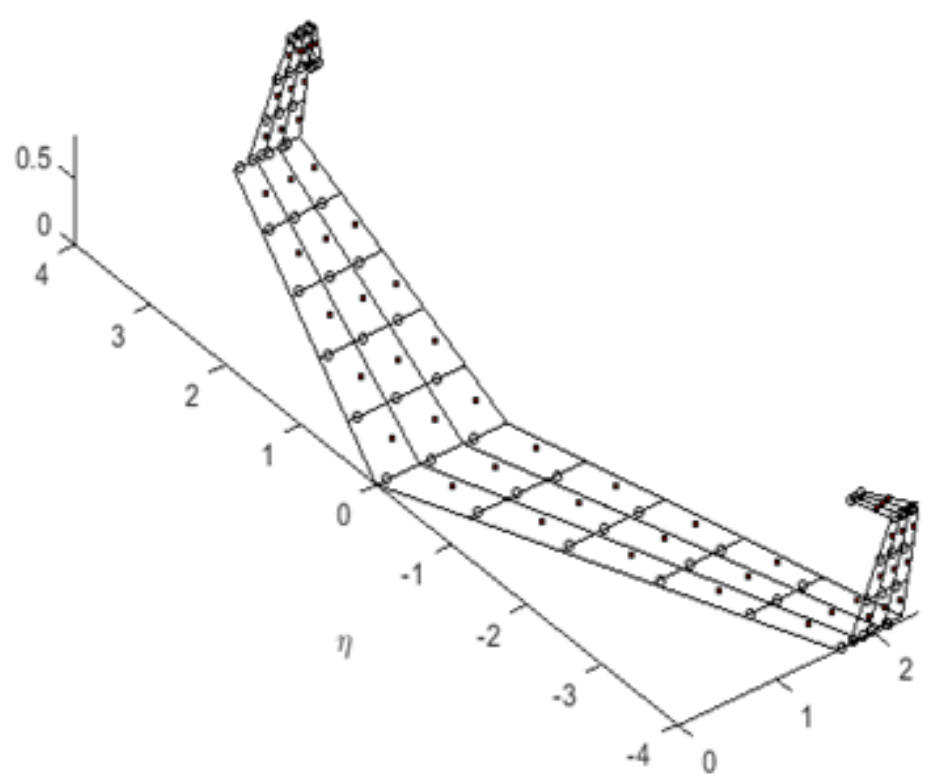

Figure 5. A swept and tapered C-wing as modeled by our VLM code. 
Computations using our code will be validated by comparison to reference numerical values. The lattice resolution used is 3 rows of panels in the chordwise direction and 25 rows per half span in the spanwise direction. Such a spanwise resolution was sufficient for accuracy to the second decimal place.

A first comparison case consists of a biplane with wings of equal span, an aspect ratio of eight and a gap-to-span ratio of 0.5 . The value of the span efficiency factor given in Blackwell (1976) is 1.6307. The numerical method used in that work was a vortex-lattice representation of the non-planar wing in the Treftz plane with an optimum lift distribution in the spanwise direction. The equivalent biplane we considered is of the same geometry except that a linear twist of $-3^{\circ}$ was applied to both wings. The value given by our code is 1.6392 . The relative difference is about $0.5 \%$.

A second case given in the same reference is that of a wing-winglet configuration with an aspect ratio of eight and a height-to-span ratio of 0.1 . The value of the span efficiency factor given in Blackwell (1976) is 1.224. The wingwinglet combination we considered is of the same geometry $\left(\mathrm{K}_{\mathrm{c}}=1\right)$ except that a linear twist of $-2^{\circ}$ was applied to the wing. The value given by our code is 1.226. The relative difference is about $0.2 \%$.

A third and final comparison is made with values of the span efficiency factor given by Kroo (2005). The wings have an aspect ratio of 8 , a height-to-span ratio of 0.2 , and no sweep. Wing twist is equal to $-3^{\circ}$ for the biplane wings and $2^{\circ}$ for the wings of the other three configurations. The lift coefficient is equal to 0.5 and the parameter $K_{c}$ is equal to unity for the wing-winglet and C-wing. As shown in Table 1, the agreement is good. The relative difference is less than $1 \%$ for three of the configurations and is equal to $2 \%$ for the $\mathrm{C}$-wing.

Table 1

Comparison of the VLM span efficiency values with those from Kroo (2005)

\begin{tabular}{|l|l|l|l|l|}
\hline Wing configuration & Box wing & C-wing & Wing-winglet & Biplane \\
\hline Kroo (2005) & 1.46 & 1.45 & 1.41 & 1.36 \\
\hline Present work & 1.47 & 1.42 & 1.41 & 1.37 \\
\hline Difference & $+0.7 \%$ & $-2 \%$ & 0 & +0.7
\end{tabular}

The winglet or fin twist angle $\theta_{w / f}$ was optimized to give the highest value of the span efficiency factor instead of the overall lift-to-drag ratio. Such a choice emanates from the fact that the induced drag of the wings represents a higher percentage of an airplane drag than does profile drag. Finding the optimal value was done manually by running the code for different values of $\theta_{w / f}$. An example of finding the "optimal" fin twist angle is shown in Figure 6 for the C-wing. The effect is similar for the wing-winglet and box wings configurations. 


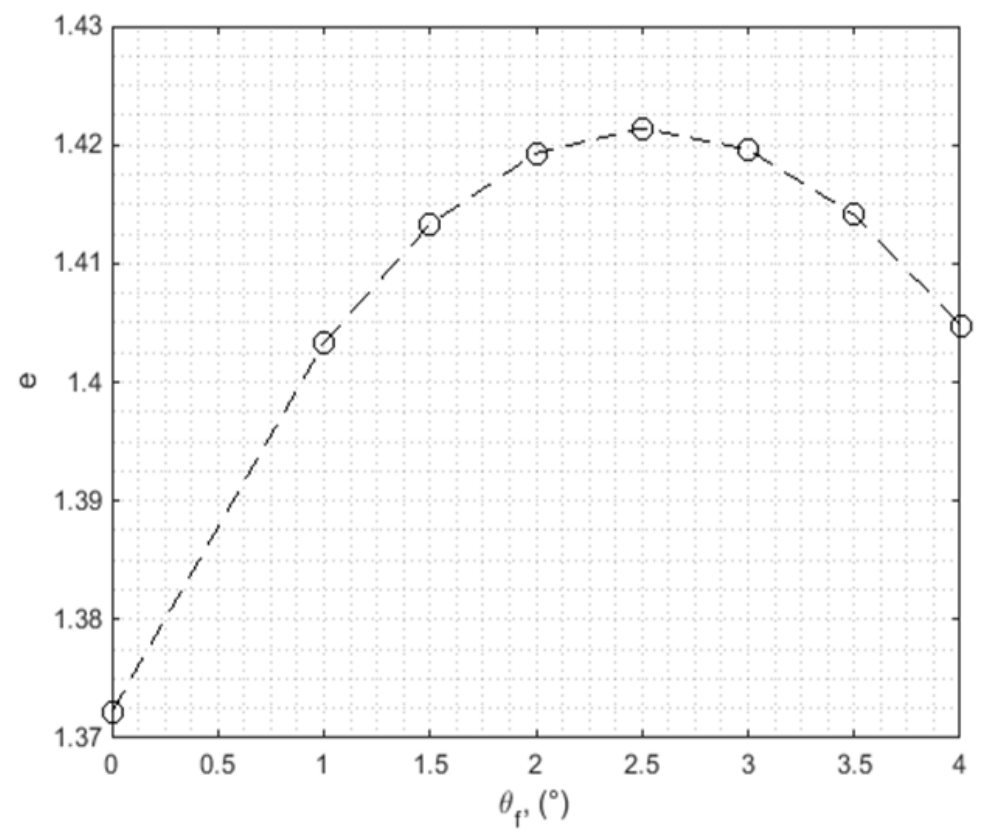

Figure 6. An example of finding fin twist angle $\left(\theta_{f}\right)$ of a $\mathrm{C}$-wing with $\mathrm{A}=8, \lambda=1$, $\Lambda=0, \mathrm{~K}_{\mathrm{h}}=0.2, \mathrm{~K}_{\mathrm{c}}=1, \mathrm{~K}_{\mathrm{b}}=0.1, \mathrm{C}_{\mathrm{L}}=0.5$.

The span of the upper part of a $\mathrm{C}$-wing was limited to $10 \%$ of the main wing span. Beyond this value (Figure 7), the span efficiency factor remains constant while the lift-to-drag ratio keeps on decreasing since the induced drag has reached stagnation while parasite drag continues to increase due to a greater wetted area. Since the span of the upper part of a $\mathrm{C}$-wing is small, no twist was applied to it. 


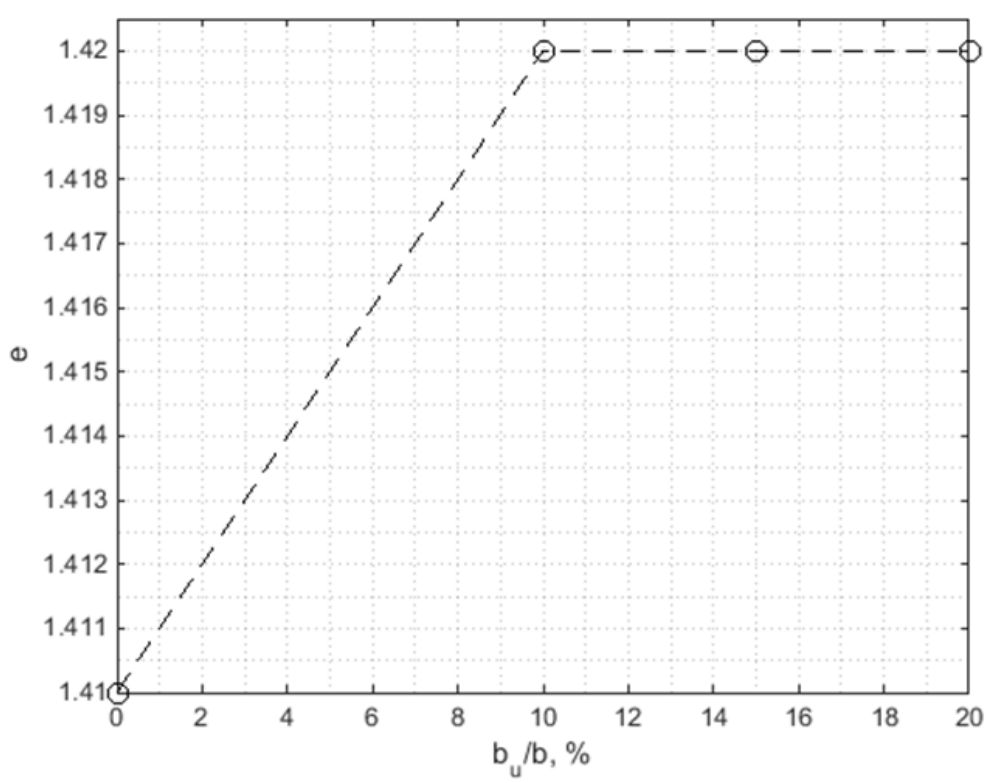

Figure 7. Variation of $e$ with the ratio of the upper wing span to overall wing span for a $\mathrm{C}$-wing with $\mathrm{A}=8, \lambda=1, \Lambda=0, \mathrm{~K}_{\mathrm{h}}=0.2, \mathrm{~K}_{\mathrm{c}}=1$, and $\mathrm{C}_{\mathrm{L}}=0.5$.

Another precaution taken was that the lift of the upper part of the $\mathrm{C}$-wing has to be of a given ratio to the lift of the lower wing. Our computations show that the upper portion's lift has to be negative and, for $K_{b}=0.1$, the ratio $L_{u} / L_{l}$ needs to be around $-0.6 \%$ to obtain higher values of $e$. This is shown on Figure 8 below. 


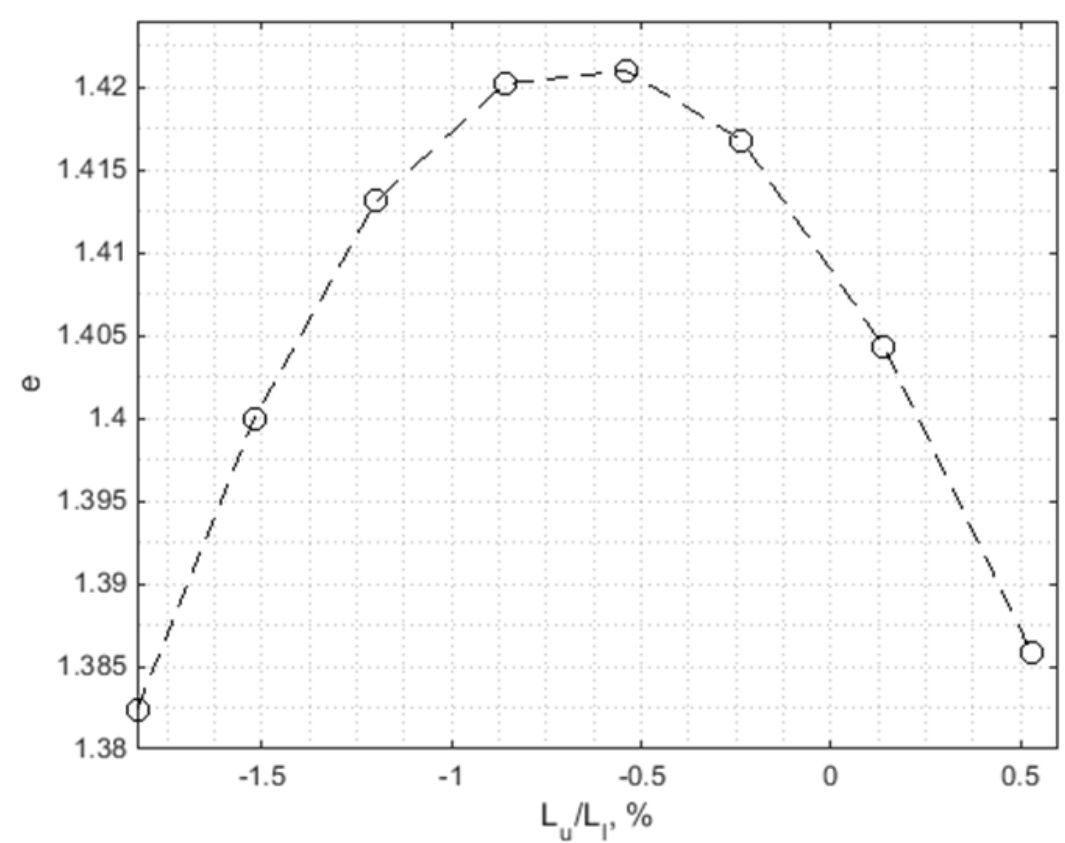

Figure 8. Effect of the ratio of upper wing lift to that of the lower wing for a $\mathrm{C}$ wing with $\mathrm{A}=8, \theta=-2^{\circ}, \lambda=1, \Lambda=0, \mathrm{~K}_{\mathrm{h}}=0.2, \mathrm{~K}_{\mathrm{c}}=1, \mathrm{~K}_{\mathrm{b}}=0.1$ at $\mathrm{C}_{\mathrm{L}}=0.5$.

For the box wing configuration, we followed the well-established fact that the lower and upper wings have to have equal positive lift while the circulation of the end fins has to equal zero at their mid points (Kroo, 2005). Similarly the wings of the biplane have to carry equal lift.

Finally, as indicated by Figure 9, compressibility had very little effect of the span efficiency factor and all computations were conducted in the incompressible régime. Compressibility effects were accounted for by applying the Prandtl-Glauert rule to the vortices circulation. 


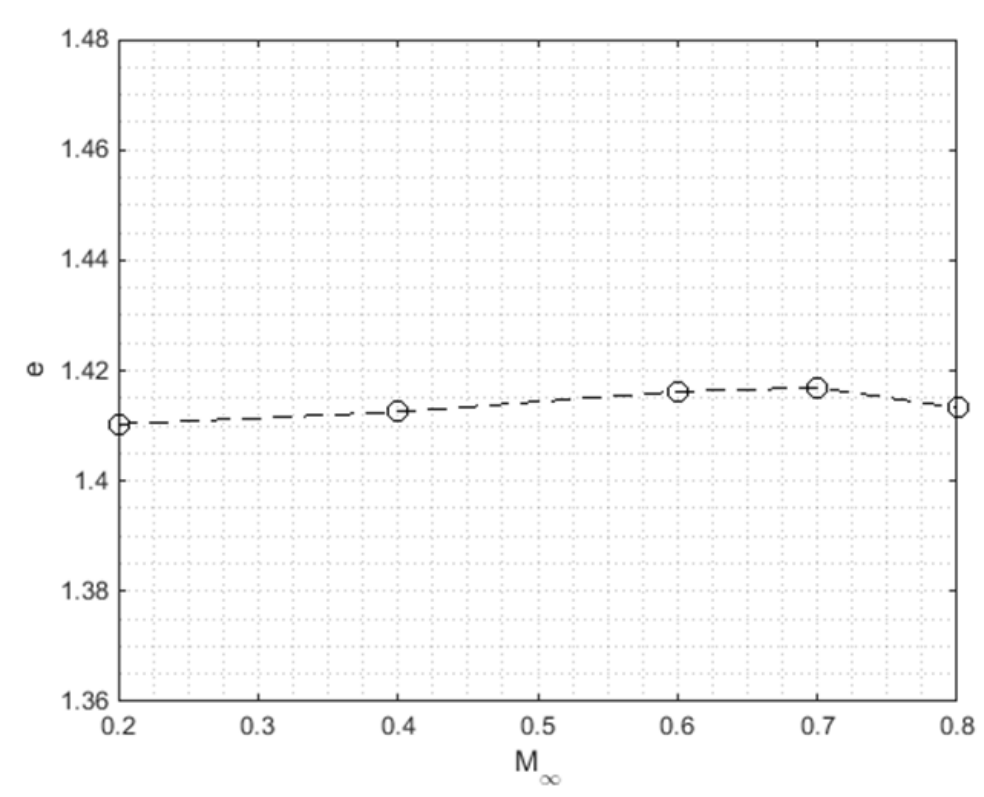

Figure 9. Effect of Mach number on the span efficiency factor: wing-winglet with $\mathrm{A}=8, \theta=-2^{\circ}, \lambda=1, \Lambda=0, \mathrm{~K}_{\mathrm{h}}=0.2, \mathrm{~K}_{\mathrm{c}}=1$, and $\mathrm{C}_{\mathrm{L}}=0.5$.

\section{Results and Discussion}

Unless otherwise specified, the aspect ratio of the different wing configurations is equal to 8 and the lift coefficient is equal to 0.5 . Such a value is representative of cruise flight. The equivalent planar wing used for comparison is a assumed to have the same aspect ratio, operate at the same lift coefficient and have an elliptic lift distribution in the spanwise direction so that its span efficiency factor is equal to unity. The induced drag coefficient is given by the equation:

$C_{D_{i}}=\frac{C_{L}^{2}}{\pi e \lambda}$

Therefore the ratio of the induced drag coefficient of any configuration to that of the reference planar wing is:

$$
r=\frac{C_{D_{i}}}{C_{D_{i_{r}}}}=\frac{e_{r}}{e}
$$

If we assume that the reference planar wing has an elliptic spanwise lift distribution at the given $\mathrm{C}_{\mathrm{L}}$ then $e_{r}=1$ and:

$r=\frac{1}{e}$ 
Since airfoil camber has basically no influence on the results, the symmetrical NACA 0012 was used for the main wing, vertical extension and upper wing. The twist of the upper wing of the box wing configuration was set equal to that of the lower wing. But no twist was given to the upper portion of the C-wing.

\section{Effect of Twist}

The effect of wing twist on the span efficiency factor is shown in Figure 10. From an aerodynamic efficiency perspective, this parameter will be chosen as to maximize the value of $e$. In practice, higher washout values may be chosen in order to obtain a better wing stall onset characteristics for instance. One should note however that, when the twist angle is varied between -4 and $0^{\circ}$, the difference between the maximum value of $e$ and its minimum is around $3 \%$ for the biplane and less than $2 \%$ for the other three configurations.

Throughout this study, unless otherwise specified, the following values for wing twist are retained:

- $\theta=-2^{\circ}$ for the wing of the wing-winglet system, the $\mathrm{C}$-wing and both wings of the box wing.

- $\theta=-3^{\circ}$ for both wings of the biplane and for the planar wing.

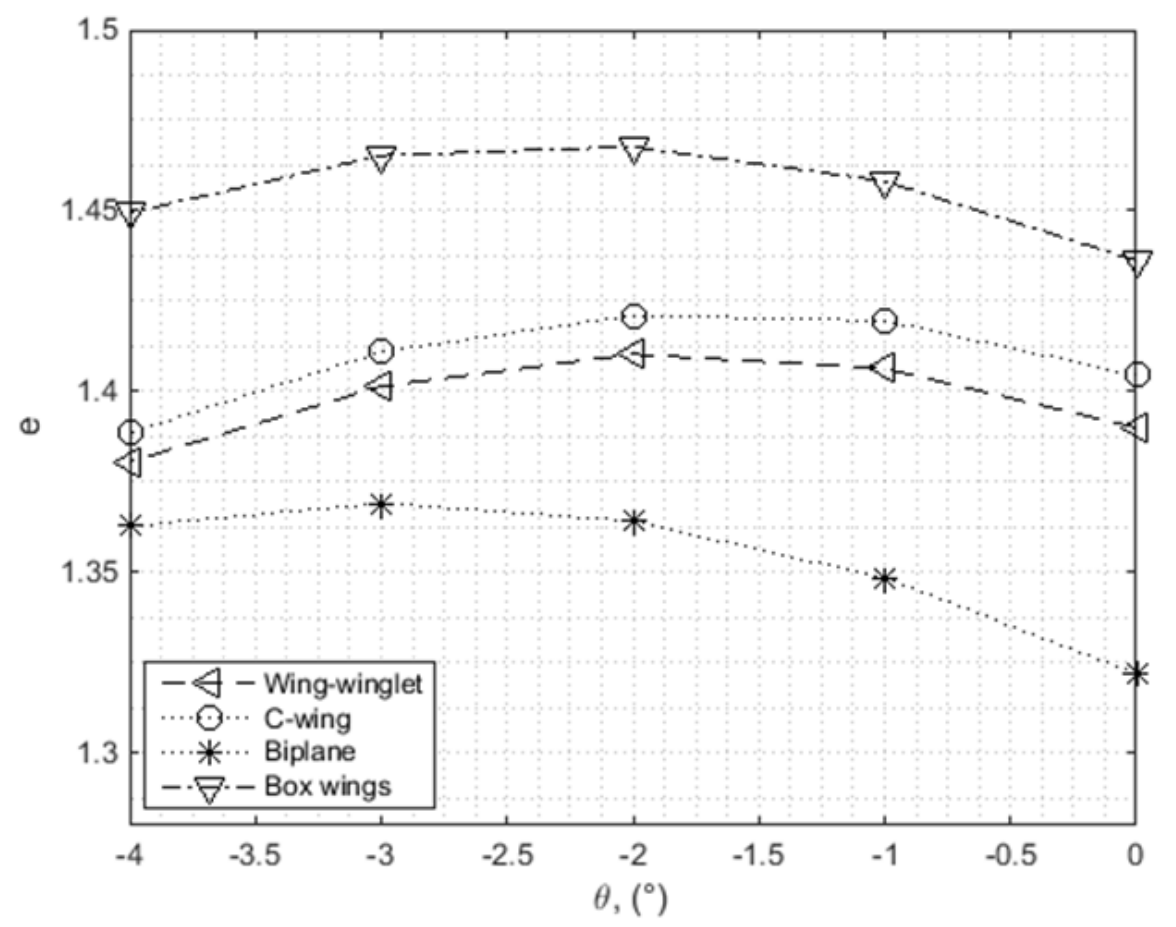

Figure 10. Effect of wing washout on $e$ for $\mathrm{A}=8, \lambda=1, \Lambda=0, \mathrm{~K}_{\mathrm{h}}=0.2, \mathrm{~K}_{\mathrm{c}}=1$, and $\mathrm{C}_{\mathrm{L}}=0.5$. 


\section{Effect of Taper}

Increasing wing taper reduces the value of the span efficiency factor. The decrease is $3.4 \%$ for the box wing, $3.7 \%$ for the biplane and $5.6 \%$ for both the Cwing, and wing-winglet configuration when going from a rectangular configuration to one with 0.5 taper ratio.

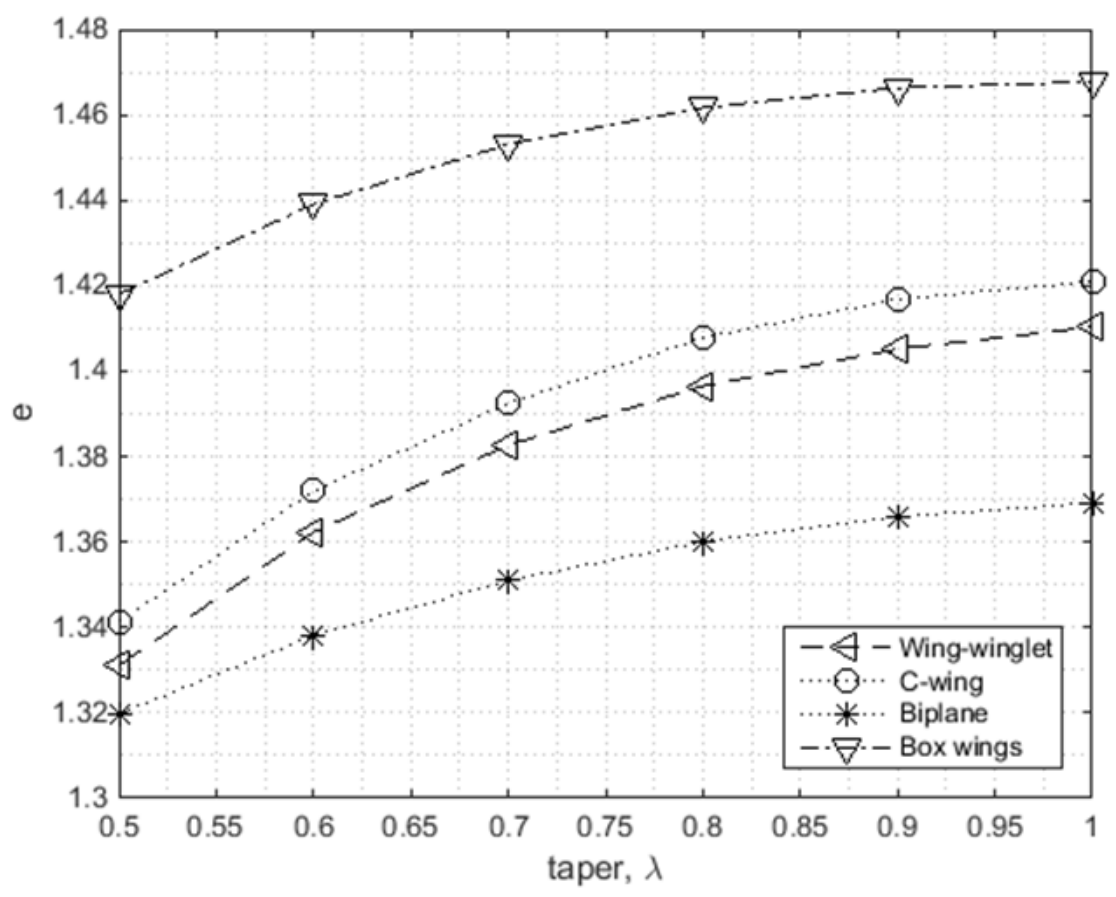

Figure 11. Effect of taper on $e$ for $\mathrm{A}=8, \mathrm{~K}, \Lambda=0, \mathrm{~K}_{\mathrm{h}}=0.2, \mathrm{~K}_{\mathrm{c}}=1$, and $\mathrm{C}_{\mathrm{L}}=0.5$.

\section{Effect of Aspect Ratio}

As for planar wings, the span efficiency factor of nonplanar configurations decreases with aspect ratio (Figure 12). However, the effective aspect ratio $(e A)$ increases linearly for all four configurations (Figure 13). Since the induced drag coefficient is inversely proportional to this parameter, it decreases with aspect ratio. It follows that, for a given lift coefficient, the $\mathrm{L} / \mathrm{D}$ ratio of the configuration increases. When $A$ is increased from 6 to 10, the increase in L/D is around 24\% for the C-wing, $25 \%$ for the wing-winglet, and $28 \%$ for the box wing and the biplane.

If we compare the $L / D$ values at $A=8$ to those at $A=6$, then the increase is still important. It is of the order of $14 \%$ for the wing-winglet and C-wing, $16 \%$ for the box wing, and $17 \%$ for the biplane. The corresponding increase in the product $e A$ is about $32 \%$ for the wing-winglet and $33 \%$ for the other three configurations. This amounts to about $25 \%$ decrease in the induced drag coefficient. 
International Journal of Aviation, Aeronautics, and Aerospace, Vol. 6 [2019], Iss. 4, Art. 10

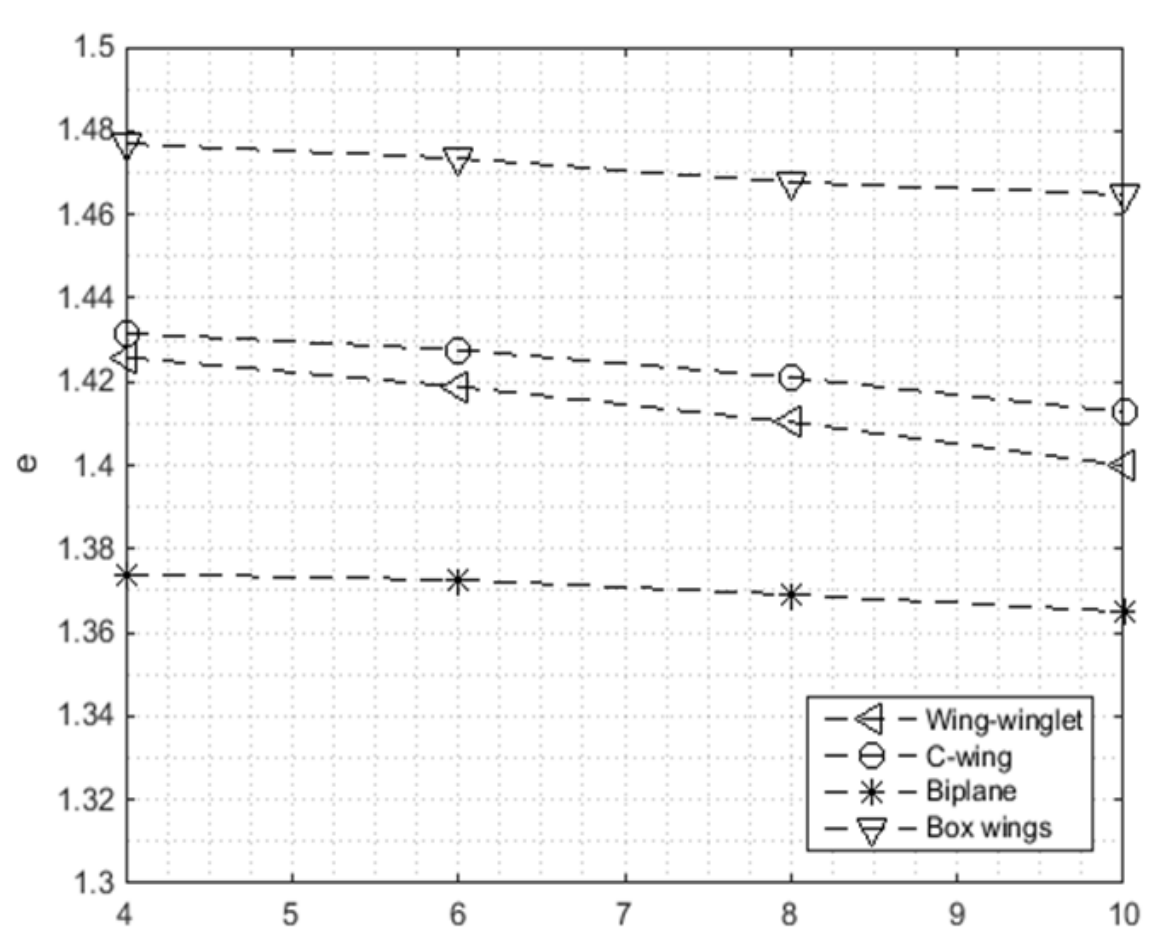

Figure 12. Variation of $e$ with aspect ratio for $\lambda=1, \Lambda=0, \mathrm{~K}_{\mathrm{h}}=0.2, \mathrm{~K}_{\mathrm{c}}=1$, and $\mathrm{C}_{\mathrm{L}}=0.5$. 


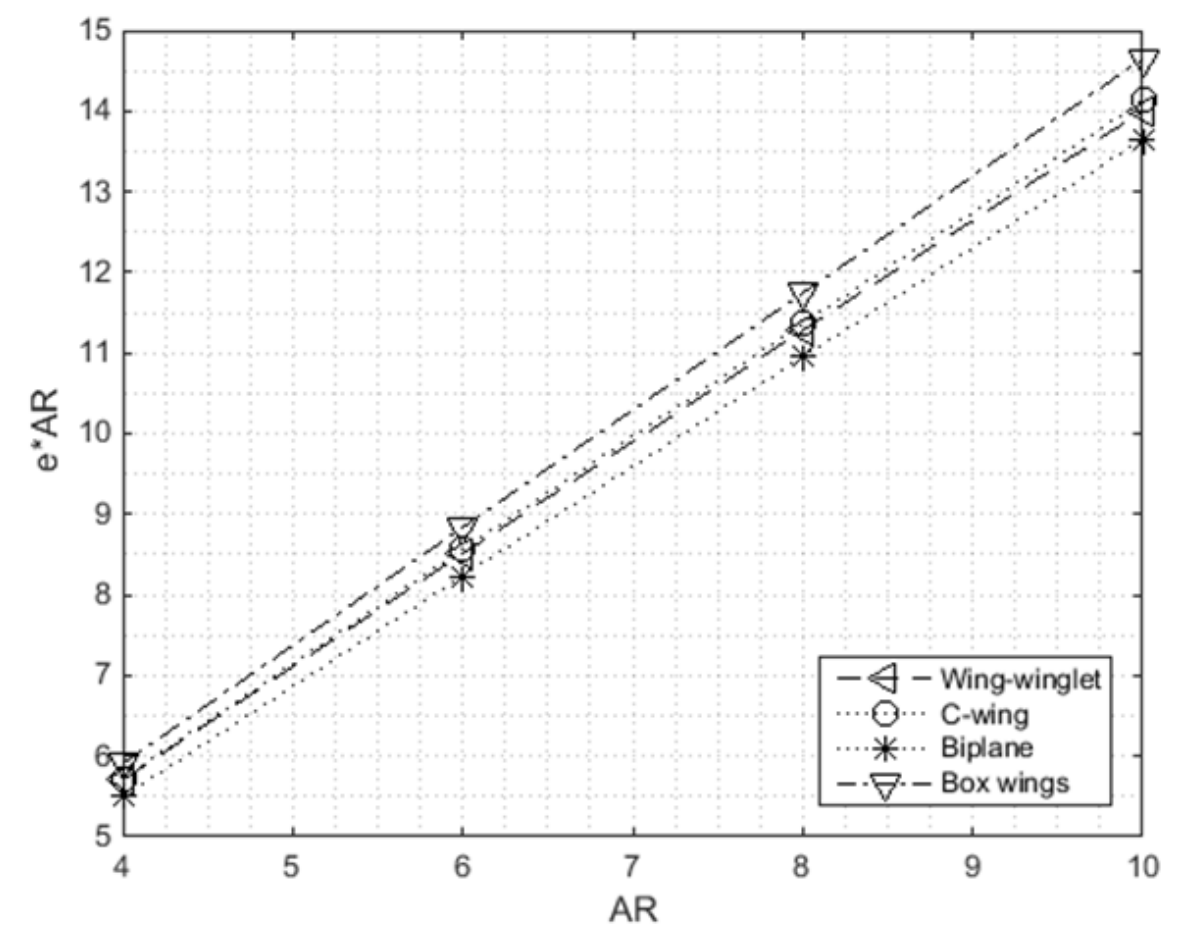

Figure 13. Variation of $e A$ with aspect ratio for $\lambda=1, \Lambda=0, \mathrm{~K}_{\mathrm{h}}=0.2, \mathrm{~K}_{\mathrm{c}}=1$, and $\mathrm{C}_{\mathrm{L}}=0.5$.

An interesting observation is that, for aspect ratios higher than 8 , an equivalent planar wing with equal aspect ratio and at the lift coefficient value of 0.5 gives higher values of L/D than the wing-winglet and $\mathrm{C}$-wing configurations (Figure 14). However, both non planar configurations still have the important advantage of a much higher span efficiency factor. That of a planar wing is at best equal to 1 . 


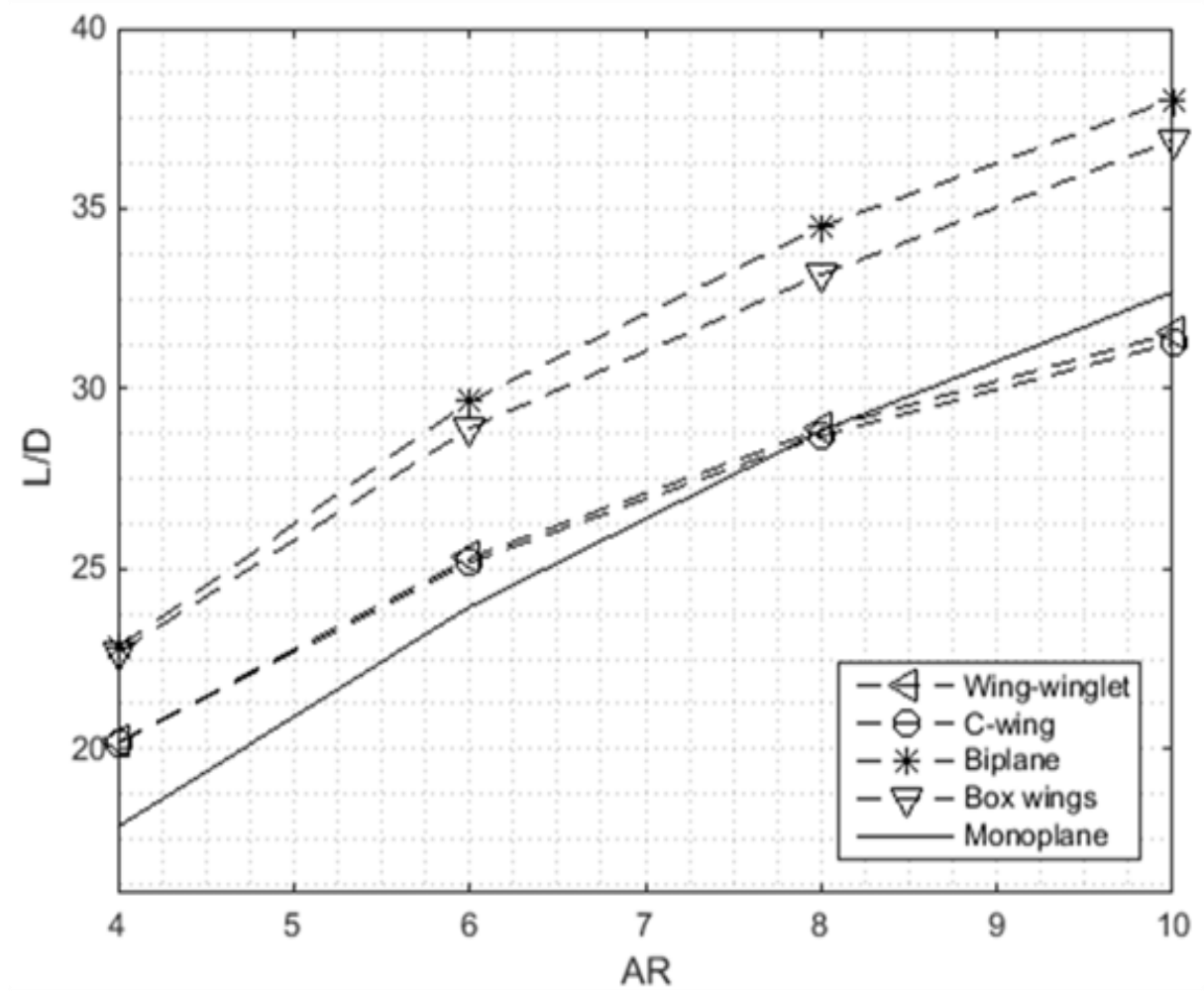

Figure 14. Variation of $L / D$ with aspect ratio for $\lambda=1, \Lambda=0, \mathrm{~K}_{\mathrm{h}}=0.2, \mathrm{~K}_{\mathrm{c}}=1$, and $\mathrm{C}_{\mathrm{L}}=0.5$.

\section{Effect of Sweep}

Moderate sweep improves the span efficiency factor. When a $20^{\circ}$ sweep at the quarter chord is applied to wings and end fins alike, the span efficiency factor $e$ increases from (Figure 15):

- 1.41 to 1.44 for a wing-winglet, a $2.1 \%$ increase.

- 1.42 to 1.46 for a C-wing, a $2.8 \%$ increase

- 1.37 to 1.40 for a biplane, a $2.2 \%$ increase

The $e$ value for the box wing increases from 1.47 to 1.48 for a sweep of $15^{\circ}$. 


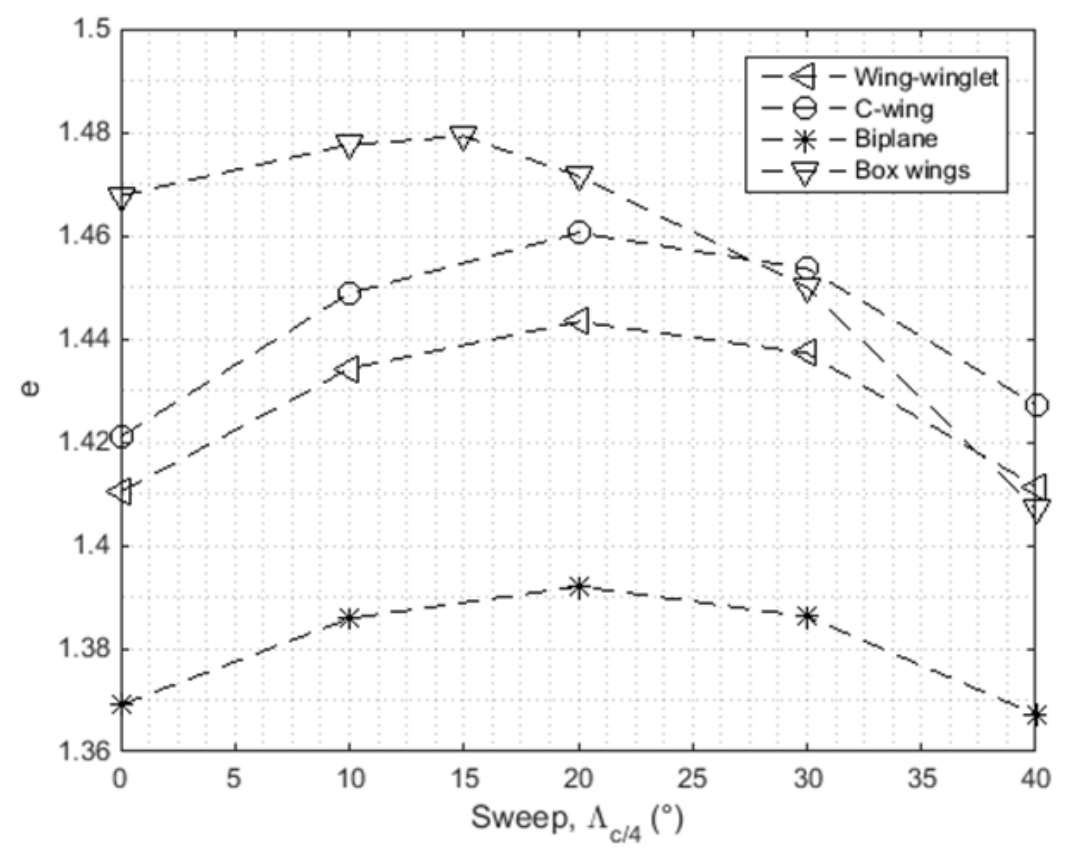

Figure 15. Effect of sweep on $e$ for $\mathrm{A}=8, \lambda=1, \Lambda=0, \mathrm{~K}_{\mathrm{h}}=0.2, \mathrm{~K}_{\mathrm{c}}=1$, and $\mathrm{C}_{\mathrm{L}}=0.5$.

\section{Effect of Chord Ratio}

This parameter is the ratio of the winglet/fin bottom chord to the tip chord of the lower wing. It concerns only the $\mathrm{C}$-wing and wing-winglet configurations. As shown on Figure 16, reducing this parameter from 1 to around 0.85 will slightly increase the span efficiency factor by a moderate $0.5 \%$. If it is reduced to 0.5 , there will be a decrease of about $1.3 \%$. So generally speaking this parameter has rather limited effect on the span efficiency factor. 


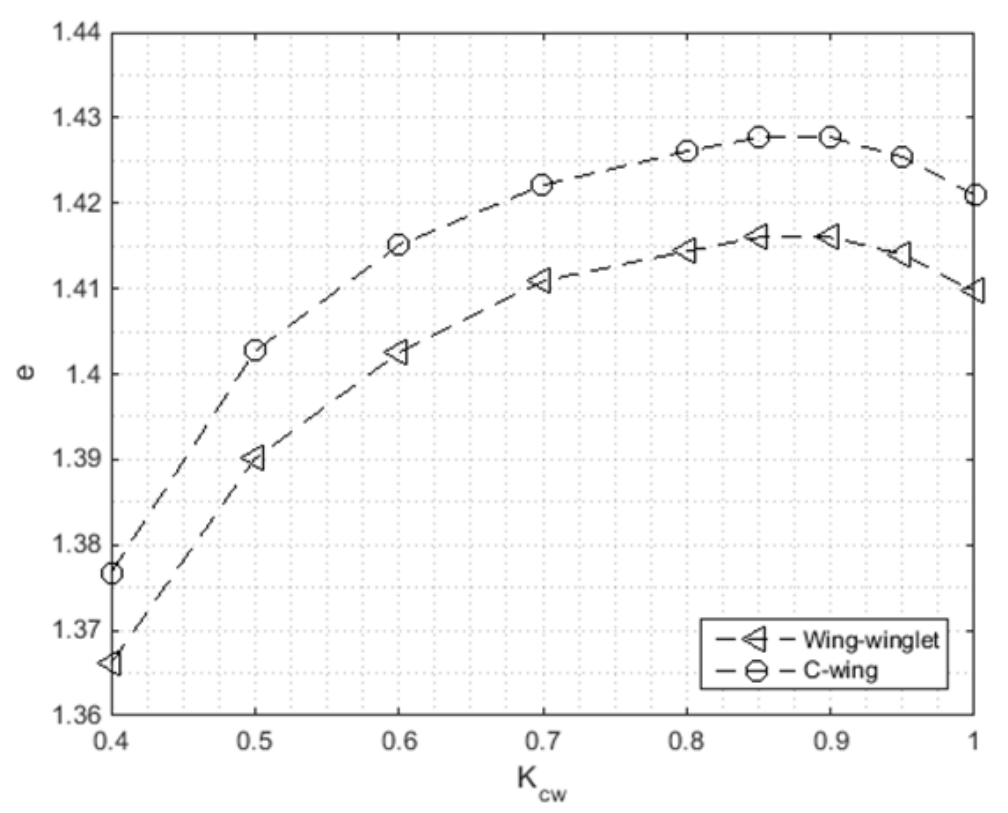

Figure 16. Effect of $\mathrm{K}_{\mathrm{c}}$ on $e$ for the $\mathrm{C}$-wing and wing-winglet for $\mathrm{A}=8, \lambda=1, \Lambda=0$, $\mathrm{K}_{\mathrm{h}}=0.2$, and $\mathrm{C}_{\mathrm{L}}=0.5$.

\section{Effect of Stagger}

For a biplane or a box wing stagger is defined as streamwise shift in position of the lower wing relative to the upper wing. It is considered positive when the former is located aft of the latter. While the stagger for the biplane is achieved directly by longitudinally shifting one of the wings with respect to the other, for the box wing configuration with straight rectangular upper and lower wings it was achieved by sweeping the fin (Figure 17).

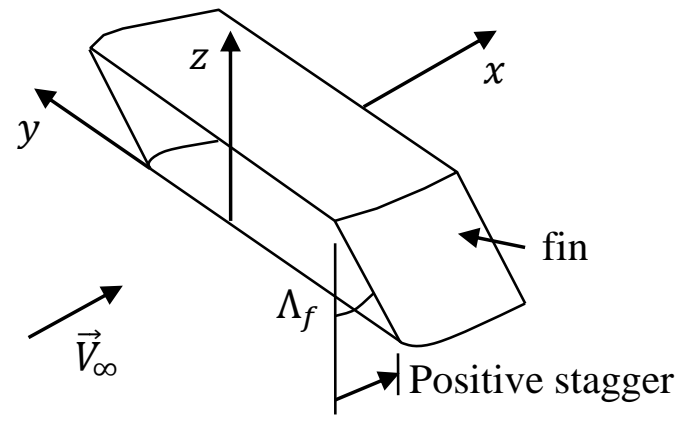

Figure 17. Definition of positive stagger for a box wing.

Based on the previous figure, the stagger normalized with respect to the average geometric chord is given by: 


$$
\begin{aligned}
& \bar{S}_{t}=S_{t} / \bar{c} \\
& =-K_{h} A \tan \Lambda_{f}
\end{aligned}
$$

where the fin sweep angle shown on this figure is considered negative.

As indicated by Figure 18, a positive stagger of an unswept rectangular biplane with an aspect ratio of 8 will moderately increase the span efficiency factor. The increase is $0.6 \%$ for a stagger of two chord lengths and about $0.9 \%$ for a stagger of three chord lengths. Negative stagger will on the other hand decrease the span efficiency factor. The decrease is about $1.4 \%$ for a negative stagger of three chord lengths.

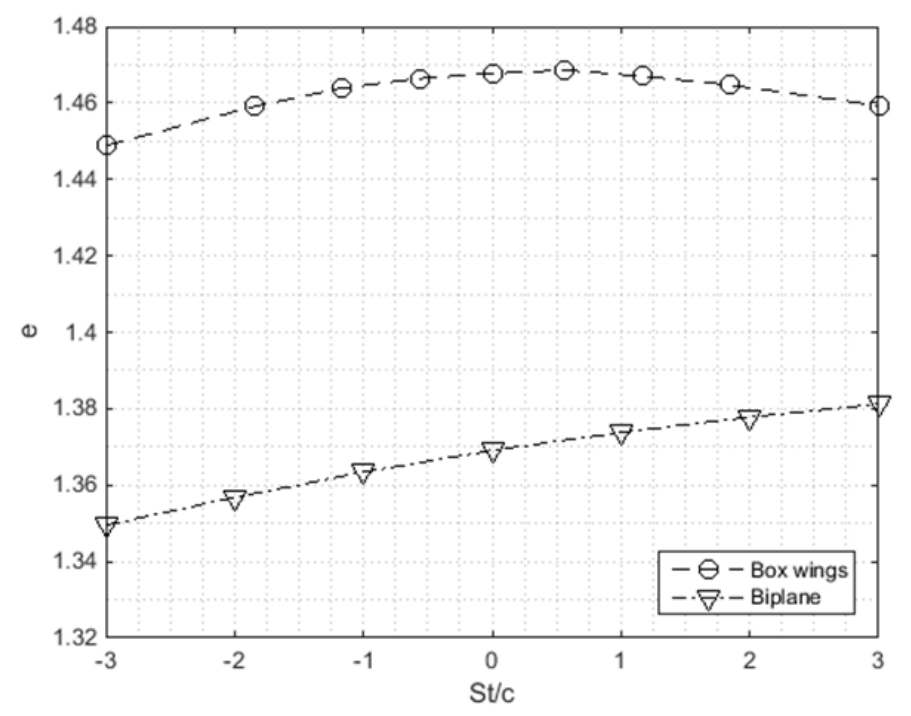

Figure 18. Effect of stagger on $e$ for the box wing and the biplane for $\mathrm{A}=8, \lambda=1$, $\Lambda=0, \mathrm{~K}_{\mathrm{h}}=0.2, \mathrm{~K}_{\mathrm{c}}=1$, and $\mathrm{C}_{\mathrm{L}}=0.5$.

The effect of stagger, positive or negative, on the box-wing system is to decrease the span efficiency factor but the change will not surpass the $1.3 \%$ for a negative stagger of three chord lengths and $0.6 \%$ for a positive stagger of equal amplitude.

Staggering the end fin for the wing-winglet or the $\mathrm{C}$-wing consisted in shifting backwards its leading edge along the main wing tip chord. Sample results for the case where the fin chord is equal to the main wing's chord are shown on Figure 19. These results show that such a measure will increase the span efficiency factor up to a relative stagger $\left(S_{t} / c\right)$ of about 0.6 to $2 / 3$. For the unswept wing-winglet configuration, the increase is $2.7 \%$ and it occurs for a relative stagger of $2 / 3$. Whereas, for the same configuration with a $20^{\circ}$ sweep, $e$ goes from 1.44 at zero stagger up to 1.49 for a relative stagger of 0.6 . The 
increase is about $3.5 \%$. For the $\mathrm{C}$-wing with a $20^{\circ}$ sweep $e$ goes up 1.46 to 1.51 with an increase of $3.4 \%$.

It seems that the combination of a positive sweep of $20^{\circ}$ and a relative stagger of about 0.6 make both the $\mathrm{C}$-wing and wing-winglet configurations surpass the box wing in terms of the highest value of $e$.

A summary of the main results for an aspect ratio of 8 and $h / b=0.2$ is given in Table 2 where the lift-to-drag ratio was also included, along with the percent increase in the L/D ratio with respect the reference planar wing. The latter has the same aspect ratio of 8 and $3^{\circ}$ washout. It has a lift to drag ratio of 28.82 at the same $C_{L}$ value of 0.5 and a Reynolds number of $6 \times 10^{6}$. The same Reynolds number was retained for the four nonplanar configurations.

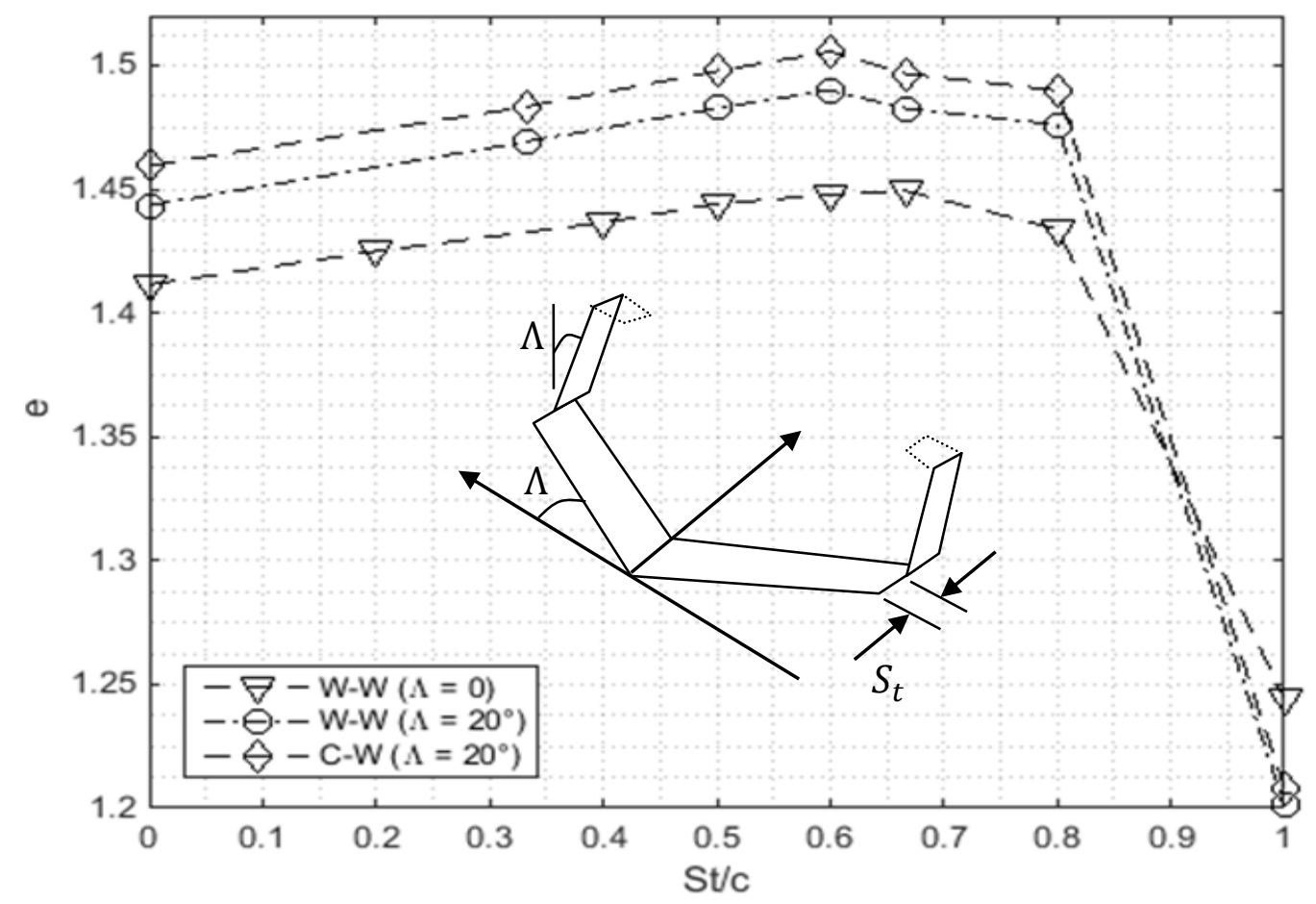

Figure 19. Wing-winglet and C-wing: effect of end fin stagger on $e$ for $\mathrm{A}=8, \lambda=1$, $\mathrm{K}_{\mathrm{h}}=0.2, \mathrm{~K}_{\mathrm{c}}=1$, and $\mathrm{C}_{\mathrm{L}}=0.5$.

The results also show that the biplane and box wing have the higher values of $L / D$ while the $\mathrm{C}$-wing configuration does not improve the lift-to-drag ratio, at least for this value of aspect ratio. Reduction in vortex drag can be viewed as more important than reducing the overall lift-to-drag ratio of the wing configuration since vortex drag takes a much higher percentage of the overall drag of an airplane than does the profile drag of the wings alone. 
Table 2

Summary of the higher values of e for $A=8, K_{h}=0.2, K_{c}=1, \lambda=1$ and $C_{L}=0.5$

\begin{tabular}{|c|c|c|c|}
\hline Wing geometry & e & L/D & $\%$ increase in $\mathrm{L} / \mathrm{D}$ \\
\hline C-wing: $\Lambda=20^{\circ}, \mathrm{St}=0.6 \mathrm{c}$ & 1.51 & 28.78 & $\approx 0 \%$ \\
\hline $\begin{array}{l}\text { Wing-winglet: } \Lambda=20^{\circ}, \mathrm{St}= \\
0.6 \mathrm{c}\end{array}$ & 1.49 & 30.00 & $4 \%$ \\
\hline Box wings: $\Lambda=15^{\circ}$ & 1.48 & 33.63 & $16.6 \%$ \\
\hline Biplane: $\mathrm{St}=2 \mathrm{c}, \Lambda=20^{\circ}$ & 1.41 & 34.37 & $19.3 \%$ \\
\hline C-wing: $\mathrm{e}=1.51$ & & \multicolumn{2}{|c|}{ Wing-winglet: $\mathrm{e}=1.49$} \\
\hline Box wing: $\mathrm{e}=1.48$ & & & plane: $\mathrm{e}=1.41$ \\
\hline
\end{tabular}

Figure 20. Higher values of $e$ for $\mathrm{A}=8, \lambda=1, \mathrm{~h} / \mathrm{b}=0.2, \mathrm{~K}_{\mathrm{h}}=0.2, \mathrm{~K}_{\mathrm{c}}=1$, and $\mathrm{C}_{\mathrm{L}}=0.5$

The positive effect associated with stagger, particularly for the C-wing and wing-winglet configurations, is not predicted by Trefftz plane analysis, frequently used in prior studies of non planar wings. This may indicate a limitation of the Trefftz plane approach as well as Munk's stagger theorem (Munk, 1921) in regard to this particular point.

\section{Effect of Cant Angle}

The cant angle is defined on Figure 21 and its effect is shown on the same figure. A negative cant angle will negatively affect the span efficiency factor for all three configurations. As for positive cant angles, our main finding is that any increase in the span efficiency factor with positive cant angles for the wingwinglet configuration (Heyson, Riebe, \& Fulton, 1977) or for the C-wing can only be claimed if the reference span is taken as that of the main wing which is lower than that the overall tip-to-tip span of the configuration. If the latter is taken as a reference, the span efficiency factor will systematically be lower since:

$$
e=\frac{L^{2}}{\pi D_{i} b^{2} \bar{q}_{\infty}}
$$

Therefore, for any given wing configuration at a given relative wind speed and angle of attack, the lift and induced drag will also have well defined values, and the choice of the value of the span will definitely define the final value of the span efficiency factor. 
For the box wing configuration, since it is generally the convention to take the higher of the upper and lower wings spans as a reference, both positive and negative angles will decrease the span efficiency factor.
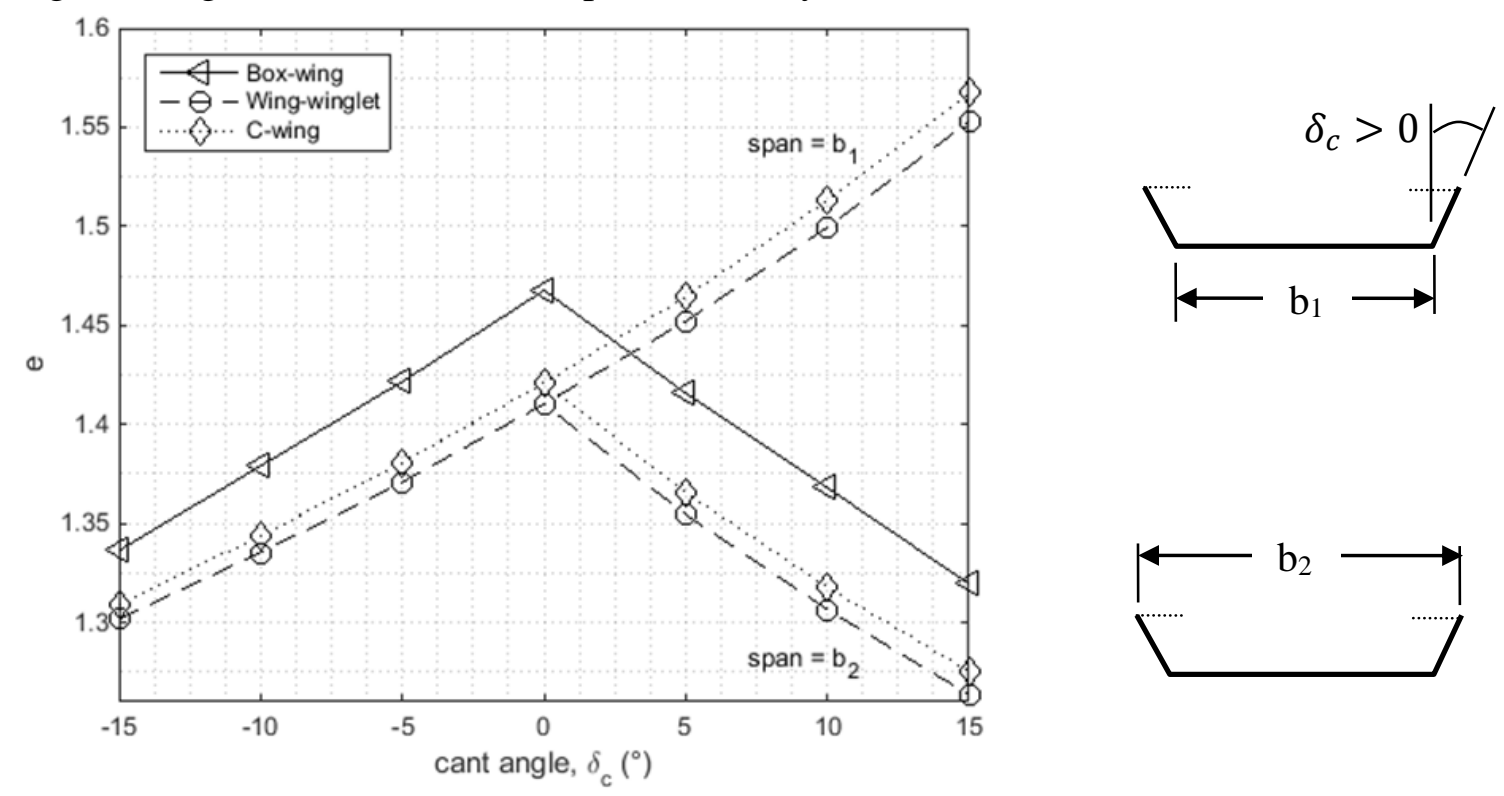

Figure 21. Effect of cant angle on $e$ for $\mathrm{A}=8, \lambda=1, \Lambda=0, \mathrm{~K}_{\mathrm{h}}=0.2, \mathrm{~K}_{\mathrm{c}}=1$, and $\mathrm{C}_{\mathrm{L}}=0.5$.

\section{Effect of Height Ratio}

The effect of the ratio of winglet/fin height to wing span is presented in terms of the ratio of the induced drag of the nonplanar configuration to that of the reference planar wing given by equation (3). The results shown on Figure 22 show that, for values of height-to-span ratio of practical interest $(0.2$ or less $)$, our results for the box wing identically duplicate what is known as the Prandtl's BWS. 


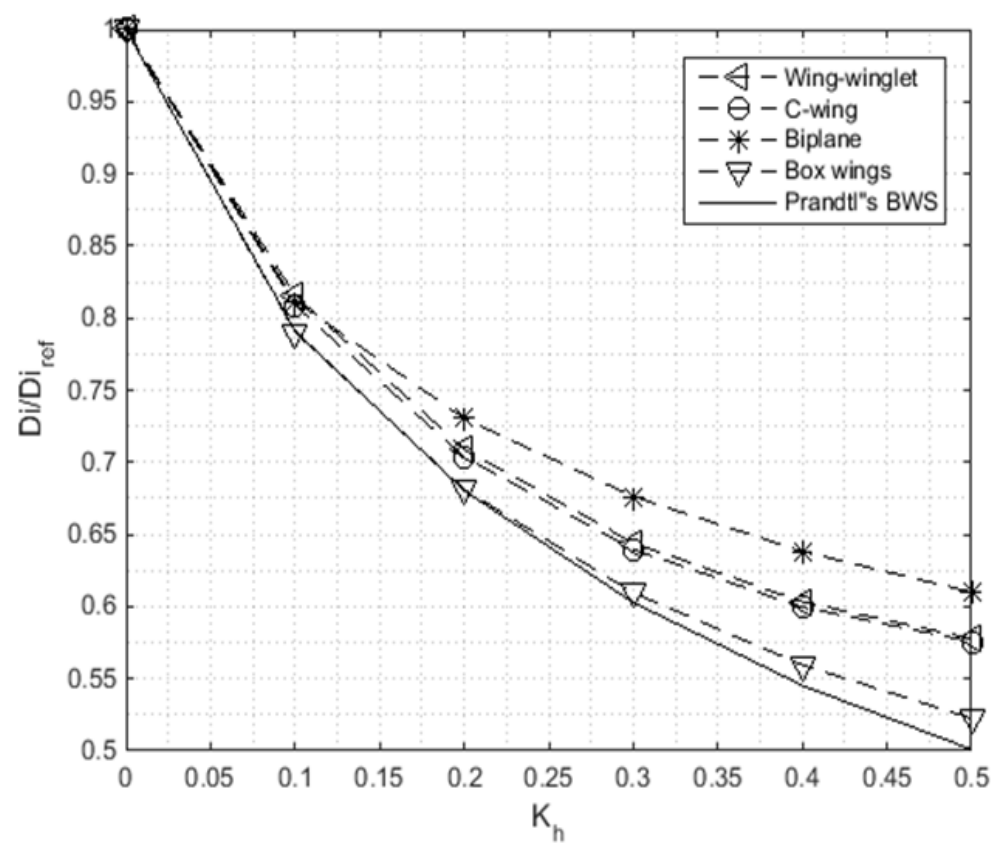

Figure 22. Effect of height-to-span ratio on $C_{D_{i}} / C_{D_{i_{r}}}$ for $\mathrm{A}=8, \Lambda=0, \lambda=1, \mathrm{~K}_{\mathrm{c}}=1$, and $\mathrm{C}_{\mathrm{L}}=0.5$.

For $\mathrm{K}_{\mathrm{h}}=0.1$, compared to the box wing, the $\mathrm{C}$-wing has $3.3 \%$ higher drag ratio, the wing-winglet $4.1 \%$, and the biplane $7.2 \%$. These differences increase with $K_{h}$.

\section{Empirical Laws for the Induced Drag Ratios}

The empirical law for the induced drag ratio is assumed to be in the form (Prandtl, 1924):

$$
r=\frac{1+r c_{1} \bar{h}}{c_{2}+c_{3} \bar{h}}
$$

where $\bar{h}$ is the height-to-span ratio and $r$ is the induced drag ratio, defined previously. The three unknown constants are determined by solving a linear system of three equations in these constants, obtained by requiring that the curve representing the induced drag ratio go through three points whose choice is somewhat arbitrary. It was found that choosing $\bar{h}_{1}=0, \bar{h}_{1}=0.2$, and $\bar{h}_{3}=0.5$ as abscissa of these points yields curve fits which fairly accurately match the discrete data (Figure 25). The three unknown constants are thereby solutions to the following system: 


$$
\left(\begin{array}{lll}
\bar{h}_{1} & -r_{1} & -\bar{h}_{1} r_{1} \\
\bar{h}_{2} & -r_{2} & -\bar{h}_{2} r_{2} \\
\bar{h}_{3} & -r_{3} & -\bar{h}_{3} r_{3}
\end{array}\right)\left[\begin{array}{l}
c_{1} \\
c_{2} \\
c_{3}
\end{array}\right]=\left[\begin{array}{l}
-1 \\
-1 \\
-1
\end{array}\right]
$$

Applying this approach to the different configurations considered we get:

- Wing-winglet:

$$
r=\frac{1+2.6 \bar{h}}{0.935+6.1 \bar{h}}, \quad \lim _{h \rightarrow \infty} r=0.426
$$

- C-wing:

$$
r=\frac{1+2.847 \bar{h}}{0.933+6.55 \bar{h}}, \quad \lim _{\bar{h} \rightarrow \infty} r=0.434
$$

\section{- Biplane:}

Present work:

$$
r=\frac{1+1.548 \bar{h}}{1.05+3.713 \bar{h}}, \quad \lim _{h \rightarrow \infty} r=0.417
$$

Prandtl's equation is:

$$
r=0.5+\frac{1-0.66 \bar{h}}{2.1+7.4 \bar{h}}, \quad \lim _{h \rightarrow \infty} r=0.411
$$

The curves corresponding to equations (9) and (10) are shown on Figure 23 and the agreement between the two approaches is quite remarkable. This is further proof of the accuracy of or VLM computations. 


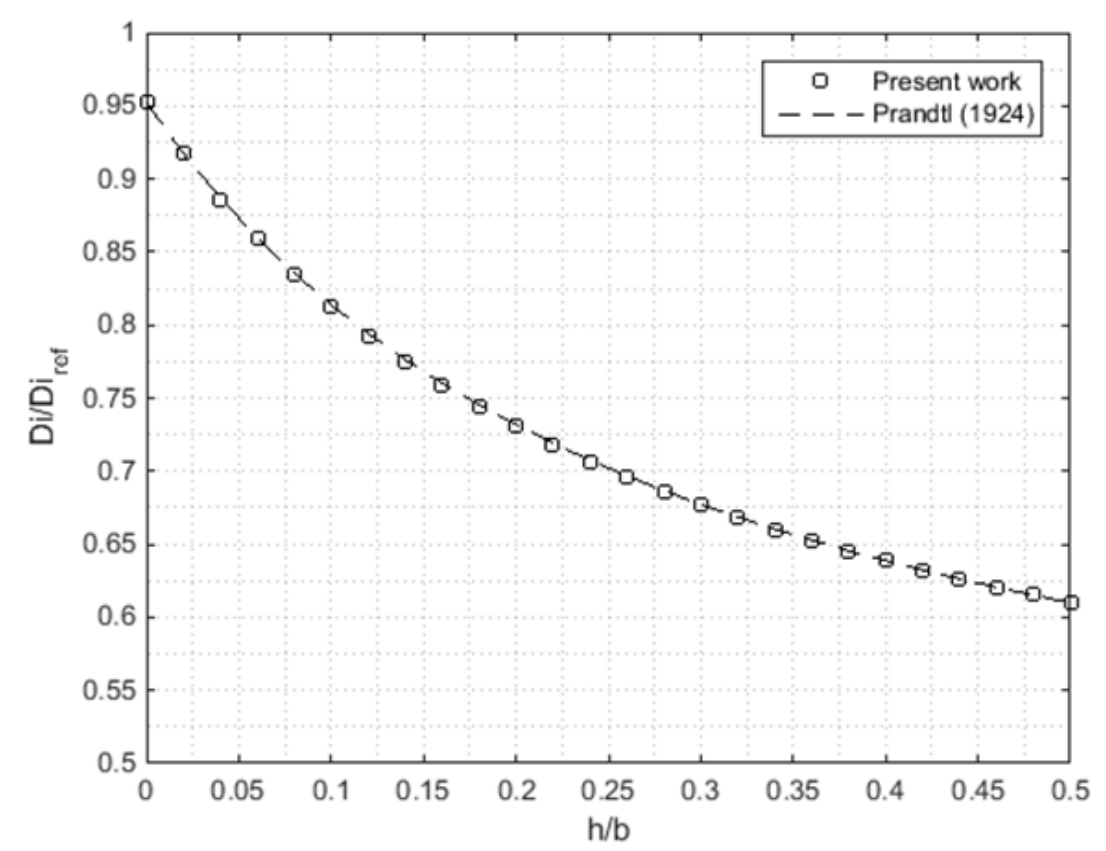

Figure 23. Comparison of the results given in the present work with those from Prandtl (1924) for the biplane configuration.

\section{- Box Wing:}

Present work:

$$
r=\frac{1+1.03 \bar{h}}{1.02+3.76 \bar{h}}, \quad \lim _{\bar{h} \rightarrow \infty} r=0.274
$$

Prandtl's result:

$$
r=\frac{1+0.45 \bar{h}}{1.04+2.81 \bar{h}}, \quad \lim _{h \rightarrow \infty} r=0.16
$$

While a more recent study (Rizzo, 2007) gave the following equation:

$$
r=\frac{1+2.18 \bar{h}}{1+5.04 \bar{h}}, \quad \quad \lim _{\bar{h} \rightarrow \infty} r=0.43
$$

The curves corresponding to equations (11)-(13) are shown on Figure 24. It is clear that in the region of practical interest, i.e. for a height-to-span ratio between 5 and $20 \%$, our results very closely agree with what is known as Prandtl's best wing system. Also, our limit value for the induced drag ratio $r$ is equal to 0.274. This places it practically midway between the ideal value of 0.16 predicted by Prandtl's analysis (Prandtl, 1924) and that given by equation (13). 


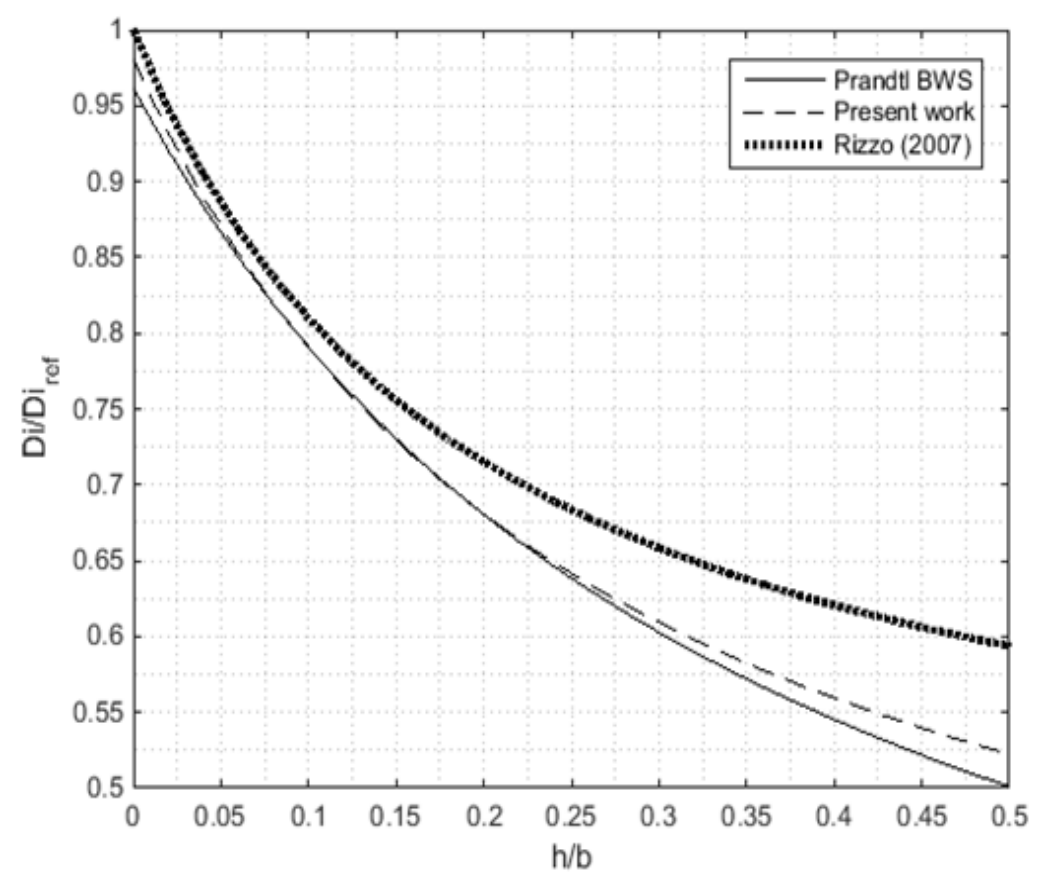

Figure 24. Comparison of the present work results and those from Rizzo (2007) for the box wing to Prandtl's best work system.

Figure 25 shows how the newly established empirical laws, given by equations (7)-(9) and (11), thoroughly agree with the numerical values of the induced drag ratio for all four configurations. 


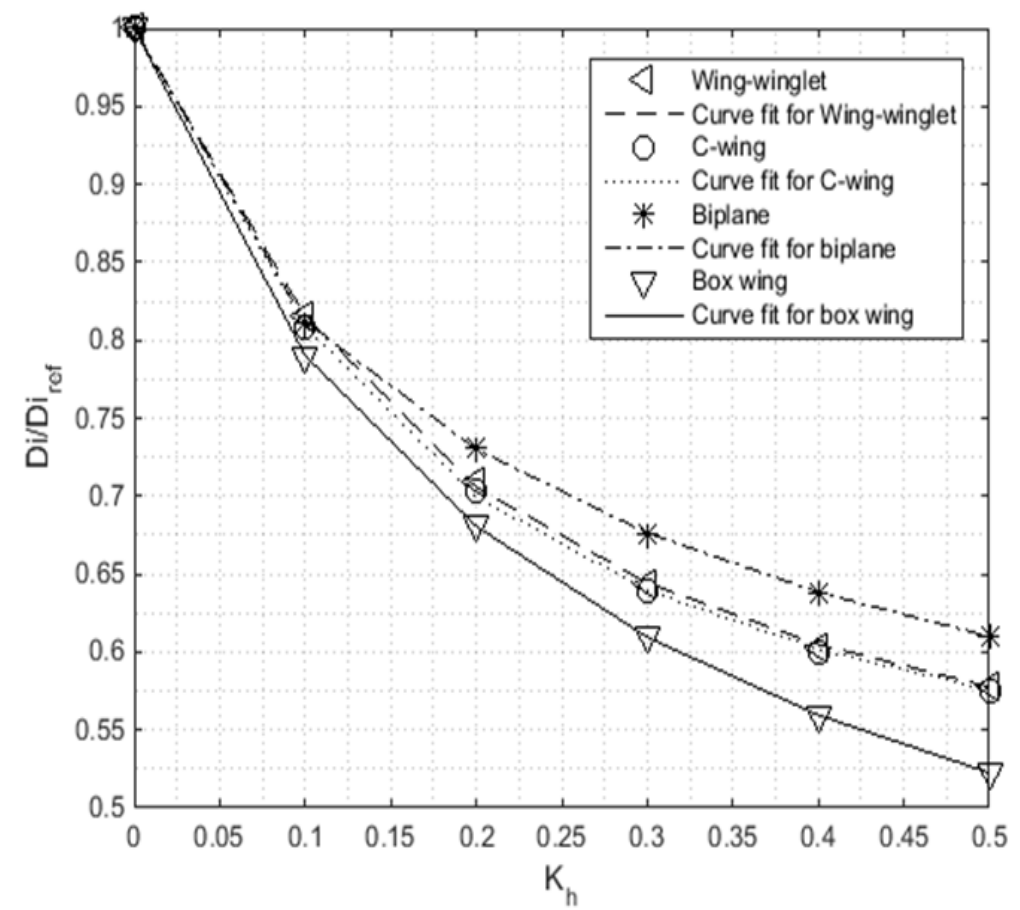

Figure 25. Agreement between the empirical laws and the numerical values of the induced drag ratio: $A=8, \Lambda=0, \lambda=1, K_{c}=1$, and $C_{L}=0.5$.

\section{Conclusions}

In this work four nonplanar wing configurations were studied using the vortex-lattice method: the wing-winglet, the $\mathrm{C}$-wing, the biplane, and the box wing. It has been shown that linear twist, which is more practical in aeronautical construction, is more than adequate when it comes to achieving the higher values of span efficiency factor obtained by a completely optimized twist distribution along the span camber, the latter being in general highly varying and thus not very practical.

It has also been shown that moderate sweep can slightly increase the span efficiency factor and further reduce vortex drag. The increase is more important for the C-wing, the wing-winglet, and the biplane than it is for the box wing. Similarly, it was found that staggering the vertical extension longitudinally backwards to around $60 \%$ of wing tip chord for the C-wing and wing-winglet configurations had a non negligible positive effect on the span efficiency factor. It was also shown that combining such a stagger and a moderate sweep gave the Cwing and the wing-winglet configurations a slight edge over the box wing configuration in terms of the value of the span efficiency factor. The latter 
configuration is known to have the higher value of this important aerodynamic parameter, but only when no sweep and stagger are applied.

When assessed from the perspective of the overall lift-to-drag ratio, the biplane and then the box wing configuration have the highest values, at least for the cruise flight lift coefficient considered. Reduction in vortex drag can be viewed as more important than increasing the lift-to-drag ratio of the wing configuration since vortex drag takes a much higher percentage of the overall drag of an airplane than does the profile drag of the wings alone. As mentioned at the beginning of this article, the vortex drag represents as much as $90 \%$ of the total drag at low speed flight and as much as $40 \%$ in cruise flight, for jet transports at least. 


\section{References}

Abbott, I. H., \& Von Doenhoff, A. E. (1959). Theory of wing sections. New York, NY: Dover.

Blackwell, J. A. (1976). Numerical method to calculate the induced drag or optimum loading for arbitrary non-planar aircraft. Retrieved from https://ntrs.nasa.gov/search.jsp?R=19760021079

Bertin, J. J., \& Smith, M. L. (2009). Aerodynamics for engineers (5th ed.). New York, NY: Pearson Prentice Hall.

Frediani A., \& Montanari G. (2009). Best wing system: An exact solution of the Prandtl's problem. In Variational Analysis and Aerospace Engineering. Springer Optimization and Its Applications, 33, 183-211.

Frediani, A. (2005). The Prandtl wing: Innovative configurations and advanced concepts for future civil transport aircraft. Van Karmon Institute for Fluid Dynamics, VKI Lecture series. Retrieved from http://www.engbrasil.eng.br/artigos/art95.pdf

Gagnon, H., \& Zingg, D. W. (2016). Aerodynamic optimization trade study of a box-wing aircraft configuration. AIAA. https://doi.org/10.2514/1.C033592

Heyson, H. H., Riebe, G. D., \& Fulton, C. L. (1977). Theoretical parametric study of the relative advantages of winglets and wing-tip extensions. Retrieved from https://ntrs.nasa.gov/search.jsp?R=19770026168

Kroo, I. (2004). A general approach to multiple lifting surface design and analysis. AIAA. https://doi.org/10.2514/6.1984-2507

Kroo, I. (2005). Nonplanar wing concepts for increased aircraft efficiency. Retrieved from http://citeseerx.ist.psu.edu/viewdoc/summary? doi=10.1.1.139.9694

Kuhlman, J., \& Ku, T. (1982). Numerical optimization techniques for bound circulation distribution for minimum induced drag of nonplanar wings: Computer program documentation. Retrieved from https://ntrs.nasa.gov/ search.jsp?R=19830022114

Lange, R. H., Cahill J. F., Bradley, E. S., Eudaily, R. R., Jenness, C. M., \& MacWilkinson, D. G. (1974). Feasibility study of the transonic biplane concept for transport aircraft application. Retrieved from https://ntrs.nasa.gov/search.jsp?R=19740026364

Lamar, J. E. (1976). A vortex-lattice method for the mean camber shapes of trimmed non coplanar planforms with minimum induced drag. Retrieved from https://ntrs.nasa.gov/archive/nasa/casi.ntrs.nasa.gov/ 19760019073.pdf

Munk, M. M. (1921). The minimum induced drag of airfoils. Retrieved from https://ntrs.nasa.gov/search.jsp?R=19930091456 
Prandtl, L. (1924). Induced drag of multi planes. Retrieved from https://ntrs.nasa.gov/search.jsp?R=19930080964

Rizzo, E. (2007). Optimization methods applied to the preliminary design of innovative, non conventional aircraft configurations. Pisa, IT: Edizioni.

Yahyaoui, M. (2014). Generalized vortex lattice method for predicting characteristics of wings with flap and aileron deflection. International Journal of Mechanical, Aerospace, Industrial, and Mechatronics Engineering, 8(10), 1690-1698.

Yahyaoui, M. (2019). A new method for the prediction of the downwash angle gradient. International Journal of Aviation, Aeronautics, and Aerospace, 6(3). Retrieved from https://commons.erau.edu/ijaaa/vol6/iss $3 / 9$ 